\title{
INTRADAY STEALTH TRADING: WHICH TRADES MOVE PRICES DURING PERIODS OF HIGH VOLUME?
}

\author{
Benjamin M. Blau \\ Utah State University \\ Bonnie F. Van Ness and Robert A. Van Ness \\ University of Mississippi
}

\begin{abstract}
Research documents a U-shaped intraday pattern of returns. We examine which trade sizes drive the $U$-shaped pattern and find that intraday price changes from larger trades exhibit a $U$-shaped pattern whereas price changes from smaller trades show a reverse U-shaped pattern. We argue that price changes from smaller trades are higher during the middle of the day because informed investors break up their trades to disguise their information when intraday volume is low. Price changes from larger trades are likely higher at the beginning and end of the day because high volume allows informed investors to increase their trade size without revealing their information to the market.
\end{abstract}

JEL Classification: G1, G14

\section{Introduction}

Research finds a peculiar intraday U-shaped pattern in returns (Wood, McInish, and Ord 1985; Harris 1986) as well as a U-shaped pattern in volume and the number of trades (Jain and Joh 1988; Chan, Christie, and Schultz 1995; Chung, Van Ness, and Van Ness 1999). The literature provides several explanations for these persistent patterns. Copeland $(1976,1977)$ shows in theory that the arrival of sequential information is disseminated to only one trader at a time, which suggests a positive correlation between volume and prices changes. Admati and Pfleiderer (1988) predict that informed trading occurs during periods of high liquidity volume, thus partially explaining the U-shaped patterns in price changes and higher volume. Foster and Viswanathan (1993) show that asymmetric information is higher at the beginning and end of the day, which supports the prediction of Admati and Pfleiderer.

The theory of Kyle (1985) posits that informed traders earn more profit when engaging in dynamic trading strategies or spreading their trades over time. Evidence of the stealth trading hypothesis, which posits that informed investors break up their trades into smaller trades to hide their information, is found by 
Barclay and Warner (1993), Chakravarty (2001), and Hansch and Choe (2007). Together with the ex ante theories explaining the intraday pattern of returns and trading activity, stealth trading suggests that smaller trades will move prices when volume is low because informed traders do not want to reveal their information to the market. During periods of high volume, informed traders are able to increase their trade sizes because high volume provides a sufficient disguise for their information.

When examining intraday price changes of different trade sizes, we find that, indeed, price changes from larger trades exhibit a U-shaped intraday pattern whereas price changes from smaller trades typically show a reverse U-shaped intraday pattern. Our results are robust to trading during different tick-size regimes. We interpret these findings to be consistent with our conjecture that periods of high volume at the beginning and end of the day motivate informed traders to use larger sizes because higher volume disguises their information. We argue that when volume is low during the middle of the day, smaller trades move prices more because informed traders are breaking up their trades to hide their information.

Karpoff(1987) surveys the evidence that reports a positive relation between volume and price changes and presents a simple model that shows that volume will be directly related to positive price changes. When further examining the relation between volume and price changes, we find that the relation is increasing across trade sizes. These results suggest that when volume is high, larger trades move prices more than smaller trades, which is consistent with our argument that informed traders can use larger trade sizes during periods of higher volume without revealing their information to the market.

Our findings present new evidence that the familiar U-shaped pattern in intraday returns is driven by larger trades. Combined with the other documented U-shaped patterns in volume and number of trades, our results support the notion that stealth trading occurs less frequently during periods of high trading activity because informed investors can reduce the time and cost of breaking up their trades and execute larger trades without revealing their information to other sophisticated traders.

\section{Prior Literature}

Kyle's (1985) theoretical model describes the behavior of insider (informed) traders in a single auction and a continuous auction setting and predicts that prices have constant volatility over time, suggesting that information is gradually incorporated into prices. By the end of trading, prices converge to their true value, or the value that reflects all relevant information. ${ }^{1}$ The equilibrium property that we are most

\footnotetext{
${ }^{1}$ The efficient market condition requires normality and martingale properties for price movements. Kyle (1985) notes that prices will follow a Brownian motion process with instantaneous variance.
} 
interested in is that informed investors will earn greater profit in the continuous auction than in the single auction. That is, informed investors maximize profits by strategically trading in a dynamic context.

Wood, McInish, and Ord (1985) document a U-shaped intraday pattern in returns and standard deviation of returns, and Jain and Joh (1988) and Chan, Christie, and Schultz (1995) find that volume and the number of trades have a U-shaped intraday pattern. In attempt to explain the intraday pattern of trading activity and returns, Admati and Pfleiderer (1988) present a model that describes the behavior of liquidity traders and informed traders and the discretion over when they trade. For instance, liquidity traders prefer to trade when trading has little effect on prices. Admati and Pfleiderer argue that this intuition suggests that liquidity traders may have an incentive to trade together. In equilibrium, informed trading will be more prevalent during periods of concentrated liquidity volume. Furthermore, the model predicts that prices will be more informative in periods of high liquidity volume because more traders become privately informed if information acquisition is endogenous.

Consistent with Admati and Pfleiderer (1988), Back and Pedersen (1998) show that volatility follows the same pattern as liquidity volume, and Foster and Viswanathan (1993) find that adverse selection costs are higher during the beginning of the day, suggesting that informed trading occurs during the first few hours of the trading day. Our objective is to examine which trade sizes drive the U-shaped pattern in intraday returns.

The theory behind the Admati and Pfleiderer (1988) model and the Kyle (1985) model provides the framework for the stealth trading hypothesis. Barclay and Warner (1993) suggest that although the theories of Kyle and of Admati and Pfleiderer predict informed investors attempt to camouflage their trades by spreading them over time or trading during periods of high volume, theories regarding informed trading strategies ignore the possibility that informed investors break up larger trades into smaller trades so as to not reveal their information. ${ }^{2}$ Barclay and Warner's original stealth trading hypothesis posits that if informed investors break up their trades into smaller trade sizes, most of the cumulative price change should occur in medium-sized trades - not too large to reveal information and not too small because of transaction costs. Barclay and Warner test the stealth trading hypothesis by examining 105 NYSE stocks that were tender offer targets in the early 1980s. Consistent with their hypothesis, they find that more than $92 \%$ of the cumulative price change occurs in medium-sized trades.

Chakravarty (2001) further investigates the stealth trading hypothesis by distinguishing between institutional and individual traders. Chakravarty's investigation is motivated by several studies that show that institutions are more informed

\footnotetext{
${ }^{2}$ Hasbrouck (1988) argues that "large" trades will contain information; therefore, stealth trading suggests that informed traders will break up "large" trades into smaller trades in attempt to hide their information.
} 
than individuals (Lo and MacKinlay 1990; Cornell and Sirri 1992; Chakravarty and McConnell 1997, 1999). Using a sample of 97 NYSE-listed stocks that experience at least a 5\% stock price increase, Chakravarty finds that nearly $80 \%$ of the cumulative price change occurs from medium-sized trades (500 to 9,999 shares) by institutions. ${ }^{3}$ Furthermore, he finds that individuals make up very little of the cumulative price change. The findings of his analysis suggest that mediumsized institutional trades are driving the evidence supporting the stealth trading hypothesis.

In their investigation into trade size clustering, Alexander and Peterson (2007) find that trades cluster on rounded sizes that are multiples of 500, 1,000, and 5,000 shares. They find that rounded trades move prices more than unrounded trades, medium-sized rounded trades in particular move prices more than other trades. Alexander and Peterson argue that these trades are likely being executed by stealth traders. To overcome the potential that trade sizes and order sizes are different, Alexander and Peterson use data on orders as well as trades and find the results to be qualitatively similar.

Both Barclay and Warner (1993) and Chakravarty (2001) use data from the $1 / 8$ th tick-size environment. ${ }^{4}$ Larger transaction costs may persuade informed investors to execute medium-sized trades as opposed to small trades. Hansch and Choe (2007) provide a thorough investigation of the stealth trading hypothesis from 1993 to 2003 and find that the distribution of informed trades shifts from mediumsized trades to small trades around 2000. They argue that part of the distributional shift is due to increased information access in the Internet age, but most of the shift is likely due to a decrease in transaction costs. Hvidkjaer (2006) finds that small sell trades by individuals outperform small buy trades by individuals, suggesting that stocks favored by individuals become overvalued and underperform stocks that are not favored by individuals. Hvidkjaer's findings suggest that individuals are relatively uninformed and add to the conclusion of Hansch and Choe that institutional investors are breaking trades into small sizes to disguise their information in the decimal tick-size environment. As transaction costs have declined, so has the lower bound on the size of stealth trades. Therefore, we anticipate finding, similar to Hansch and Choe, that most of the cumulative price change occurs in small (medium-sized) trades using data from 2005 (1995 and 1998).

Hasbrouck (1988) suggests that trade sizes provide important insights into the behavior of informed investors. We attempt to combine the theoretical predictions of Kyle (1985) and Admati and Pfleiderer (1988) with the stealth trading

\footnotetext{
${ }^{3}$ Chakravarty (2001) argues that stocks with at least a 5\% price increase will provide a higher probability of detecting stealth trading.

${ }^{4}$ Alexander and Peterson (2007) use TORQ data from 1991 and TAQ data from 1995, 1998, and 2002 to control for the tick size changes. They find that the price impact of medium-sized trades is larger than the price impact of small trades for a sample of stocks in 2002 (which is during the decimalization period).
} 
framework to determine which trades sizes move prices during the intraday. As Kyle argues, profit-maximizing, informed investors will choose an optimal trading strategy while accounting for time, which implies that informed investors may spread trades over time. Admati and Pfleiderer suggest that informed investors will trade during periods of high volume, not only because they wish to hide their information but also because markets are "thick," meaning their trades will not substantially move prices. Combining the theoretical predictions of Kyle and Admati and Pfleiderer, we expect that informed investors will execute larger trades during periods of high volume and break up their trades during periods of low volume.

\section{Data Description}

Similar to Chakravarty (2001), we use a sample of NYSE-listed stocks for 64 trading days in three years. Following tests of stealth trading by Alexander and Peterson (2007), we use three periods to compensate for different tick-size environments. In 1995 and 1998, stocks were traded in 1/8ths and 1/16ths, respectively. Since 2001, stocks trade in decimals. ${ }^{5}$ To account for the different tick-size environments, we examine the second quarter (April 1 to June 30) of 1995, 1998, and 2005 and use the 200 most active (in terms of average daily volume) NYSE stocks for the second quarter of 1995, 1998, and 2005 (as long as the price is at least \$5).

We obtain trade data from the Trades and Quotes (TAQ) database. We separate trades into trade size categories following Barclay and Warner (1993), Chakravarty (2001), Alexander and Peterson (2007), and Hansch and Choe (2007). Small trades are trades of 100-499 shares, medium trades are 500-9,999 shares, and large trades are greater than or equal to 10,000 shares. We also define finer medium trade-size categories similar to past research. Medium-low trades are trades of 5001,999 shares, medium-mid trades are 2,000-5,999 shares, and medium-high trades are 6,000-9,999 shares. We break up the trading day into seven intervals.

We recognize an important limitation in our ability to test the stealth trading hypothesis during the intraday. Our preference is to use order data rather than trade data because of the possibility that orders are split and that the true trade size choice of the investor is not reflected in the trade size. However, we are unable to obtain order data and make the assumption that larger trades at the beginning and end of the trading day are highly correlated with larger orders. Alexander and Peterson (2007) use TORQ data from 1991, which is the only publicly available database

\footnotetext{
${ }^{5}$ Barclay and Warner (1993) argue that informed investors will break up larger trades into mediumsized trades to avoid revealing their information and redundant transaction costs. Hansch and Choe (2007) find that around the time of decimalization, the distribution of informed trades shifts from medium-sized trades to small trades. They argue that although some of the shift is caused by individual investors being better able to obtain information in the information age, most of the distributional shift is likely from institutional investors breaking up trades into small sizes to avoid revealing their information.
} 
that consists of both orders and trades. They look for differences in trades and orders and argue, "If [no noticeable differences] are observed, then trade-size results using samples from larger and more recent TAQ data are likely applicable to orders" (p. 438). After examining TORQ data, they find that trade sizes are not significantly different from order sizes and the results appear robust for all trade-size categories. Therefore, they argue that using trade data instead of order data does not bias their results.

Table 1 presents an initial test of the U-shaped intraday pattern of trading activity for each subsample. Panel A shows the difference between the number of trades in each intraday interval and the intraday mean for small, medium, and large trades in each tick-size regime. Similar to Chan, Christie, and Schultz (1995), we find a U-shaped pattern in the number of trades. Panel B examines the intraday pattern of volume for each trade size and shows that intraday volume for each trade size is U-shaped. Panels $\mathrm{C}$ and $\mathrm{D}$ report the results for the different medium tradesize categories. The U-shaped pattern is generally found in the number of trades and intraday volume across the subsamples. The medium-high trade-size category does not exhibit a U-shaped pattern in volume for the 1998 and 1995 subsamples.

\section{Methods and Empirical Results}

\section{Methods}

To determine which trade size drives the U-shaped intraday pattern in returns, we follow the methods of Barclay and Warner (1993), Chakravarty (2001), and Huang (2002). The weighted price contribution (WPC) for each trade size in each interval is estimated to capture the contribution to a stock's price change by trades classified in specific trade sizes. We first define the price change as the difference between the current trade price and the price at the last trade. We calculate the cumulative price change by summing all price changes that occur in a given trade-size category for each stock over the sample of observations. We divide this sum by the cumulative price change for each stock and then estimate the weighted cross-sectional mean of the cumulative price change where the weights are the absolute value of the cumulative price change for each stock over the sample period. ${ }^{6}$ We calculate the percentage of the cumulative price change in each trade-size category for seven intraday time intervals.

Although other measures of informed trading exist, Huang (2002) argues that the WPC is preferred to other measures because of its flexibility in

\footnotetext{
${ }^{6}$ Barclay and Warner (1993) argue that weighting the sum of the price changes in a trade-size category divided by the total sum of price changes for each stock by the absolute value of the cumulative price change controls for potential heteroskedasticity, particularly for firms with small cumulative price changes.
} 


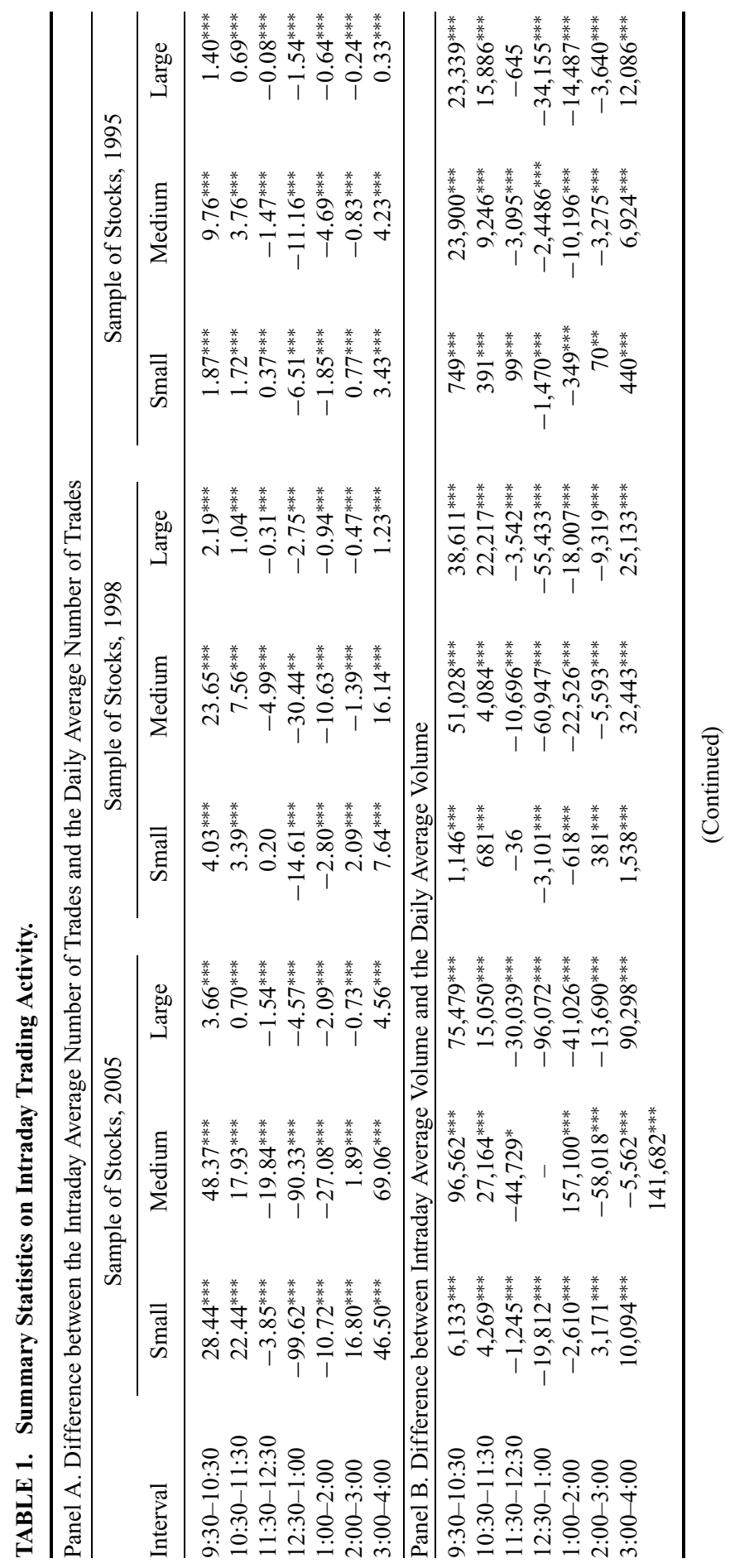




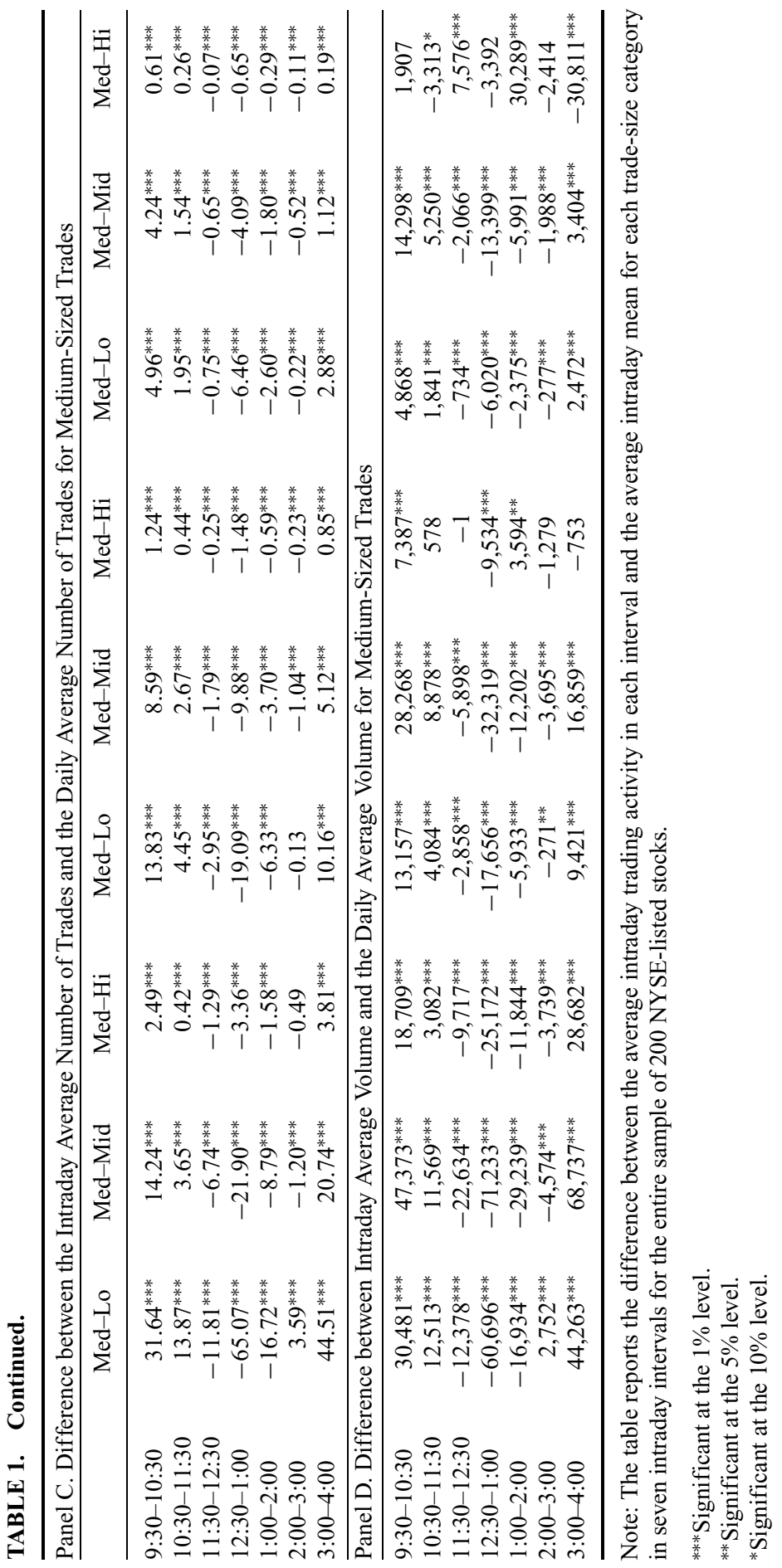


cross-sectional analyses. Furthermore, Hansch and Choe (2007) use the WPC along with two other measures: the information share (Hasbrouck 1995) and the common factor weights (Gonzalo and Granger 1995). Because they do not find qualitatively different results between the measures, we use Barclay and Warner's (1993) original stealth trading measure. ${ }^{7}$ Similar to Chakravarty (2001), we also calculate the average price change per unit volume to isolate the magnitude of the price change relative to the trade size. We examine the cumulative and average price changes during the intraday intervals and expect that price changes from larger trades will be greater at the beginning and end of the day and price changes from smaller trades will be greater during the middle of the trading day.

\section{Empirical Results}

We begin our analysis by examining whether stealth trading exists in our sample of stocks for each period. Table 2 reports the WPC for each trade size along with the trading activity measures discussed in Table $1 .{ }^{8}$ For the 2005 sample, we find that small trades make up approximately $80 \%$ of the cumulative price change whereas they reflect only $55 \%$ of the number of trades and $12 \%$ of volume. These results are consistent with Hansch and Choe (2007) and Blau, Van Ness, and Van Ness (2008). We also find that stealth trading is persistent during years in the $1 / 16$ th and $1 / 8$ th tick-size environment. Panel B reports that before decimalization, the WPC of medium-sized trades is $70 \%$ in 1998 and $63 \%$ in 1995 . These estimates are consistent with Chakravarty (2001), who documents that the cumulative price changes for medium-sized trades range from $65 \%$ to $78 \%$.

Next, we examine the WPC of different-sized trades during seven intraday intervals. If stealth trading occurs less during periods of high trading activity, which are found at the beginning and end of the day in Table 1, the WPC for smaller trades will be less during the beginning and end of the day and the WPC for larger trades will be greater during the beginning and end of the day. Looking at the first column of Table 3, Panel A, we find that the percentage of the cumulative price change for small trades is substantially less during the first hour of trading than during the entire trading day. For the first hour of the day, $68.14 \%$ of the cumulative price change is made up of small trades whereas $32.93 \%$ of the cumulative price change is made up of medium trades. It appears that some of the distribution of informed trades shifts from small trades to medium trades during the first hour. However, contrary to our hypothesis, we find that in the last hour of the trading day, small trades make up the more of the percentage of the cumulative price change than

\footnotetext{
${ }^{7}$ Cao, Ghysels, and Hatheway (2000) and Barclay and Hendershott (2003) also use the WPC when examining after-hours trading.

${ }^{8} \mathrm{We}$ exclude the first trade of each day for each stock because of the likelihood that the first trade is a batch of smaller trades.
} 
TABLE 2. Percentage of Cumulative Price Change and Trading Activity.

\begin{tabular}{|c|c|c|c|c|c|}
\hline \multicolumn{6}{|l|}{ Panel A. Sample of Stocks, 2005} \\
\hline Trade Size & $\begin{array}{l}\% \text { of Cumulative } \\
\text { Price Change }\end{array}$ & $\begin{array}{l}\text { Number } \\
\text { of Trades }\end{array}$ & $\begin{array}{l}\% \text { of } \\
\text { Trades }\end{array}$ & Volume & $\begin{array}{c}\% \text { of } \\
\text { Volume }\end{array}$ \\
\hline Small (100-499 shares) & $80.79 \%$ & $81,728.40$ & $55.35 \%$ & $15,937,401$ & $11.69 \%$ \\
\hline Medium $(500-9,999)$ & $20.92 \%$ & $64,706.01$ & $42.66 \%$ & $108,468,258$ & $60.37 \%$ \\
\hline Medium-Lo $(500-1,999)$ & $26.85 \%$ & $47,622.60$ & $31.56 \%$ & $43,958,771$ & $27.54 \%$ \\
\hline Medium-Mid $(2,000-5,999)$ & $-4.31 \%$ & $14,902.26$ & $9.70 \%$ & $48,142,643$ & $25.24 \%$ \\
\hline Medium-Hi $(6,000-9,999)$ & $-1.62 \%$ & $2,181.16$ & $1.40 \%$ & $16,332,845$ & $7.60 \%$ \\
\hline Large $(10,000+)$ & $-1.71 \%$ & $3,023.66$ & $2.04 \%$ & $71,802,893$ & $27.93 \%$ \\
\hline \multicolumn{6}{|l|}{ Panel B. Sample of Stocks, 1998} \\
\hline Small (100-499 shares) & $14.01 \%$ & $11,429.97$ & $32.35 \%$ & $2,371,592$ & $2.98 \%$ \\
\hline Medium $(500-9,999)$ & $70.34 \%$ & $21,592.24$ & $61.55 \%$ & $42,717,783$ & $50.39 \%$ \\
\hline Medium-Lo $(500-1,999)$ & $36.87 \%$ & $13,671.86$ & $39.00 \%$ & $12,587,401$ & $15.59 \%$ \\
\hline Medium-Mid $(2,000-5,999)$ & $28.33 \%$ & $6,892.65$ & $19.55 \%$ & $22,499,396$ & $26.07 \%$ \\
\hline Medium-Hi $(6,000-9,999)$ & $5.14 \%$ & $1,027.72$ & $3.00 \%$ & $7,630,986$ & $8.73 \%$ \\
\hline Large $(10,000+)$ & $15.65 \%$ & $1,997.63$ & $6.10 \%$ & $41,389,895$ & $46.63 \%$ \\
\hline \multicolumn{6}{|l|}{ Panel C. Sample of Stocks, 1995} \\
\hline Small (100-499 shares) & $13.80 \%$ & $4,953.50$ & $34.03 \%$ & 995,905 & $2.29 \%$ \\
\hline Medium $(500-9,999)$ & $63.11 \%$ & $8,181.55$ & $56.95 \%$ & $17,587,434$ & $38.51 \%$ \\
\hline Medium-Lo $(500-1,999)$ & $27.39 \%$ & $4,739.79$ & $33.23 \%$ & $4,361,925$ & $9.92 \%$ \\
\hline Medium-Mid $(2,000-5,999)$ & $28.38 \%$ & $2,969.12$ & $20.31 \%$ & $9,701,701$ & $20.94 \%$ \\
\hline Medium-Hi $(6,000-9,999)$ & $7.35 \%$ & 472.65 & $3.41 \%$ & $3,523,808$ & $7.64 \%$ \\
\hline Large $(10,000+)$ & $23.10 \%$ & $1,172.94$ & $9.01 \%$ & $27,557,593$ & $59.20 \%$ \\
\hline
\end{tabular}

Note: The percentage of cumulative price change is calculated as in Barclay and Warner (1993) and Chakravarty (2001). Panel A reports the results using the data from the second quarter of 2005, and Panel B (Panel C) uses data from the second quarter of 1998 (1995).

during any other interval. These results may be explained by the findings of Foster and Viswanathan (1993), who document that asymmetric information is higher at the beginning of the day than during the rest of the trading day, suggesting that more private information is being traded at the beginning of the day. In columns 4 though 6, we find that the distribution of informed trades shift from medium trades to large trades during the last hour of the trading day. However, it appears that in the first hour of trading, medium trades make up more of the cumulative price change than during any other interval. In the 1995 sample, we do not find the expected intraday pattern for medium trades.

To provide statistical tests of whether price changes for larger (smaller) trades increase (decrease) during periods of higher volume, we perform the following regression.

$$
\begin{aligned}
W P C_{i, t}= & \beta_{0}+\beta_{1} \text {Time }_{-} 1+\beta_{2} \text { Time } \_2+\beta_{3} \text { Time_3 } 3+\beta_{4} \text { Time } 5 \\
& +\beta_{5} \text { Time } 56+\beta_{6} \text { Time } 7+\varepsilon_{i, t} .
\end{aligned}
$$




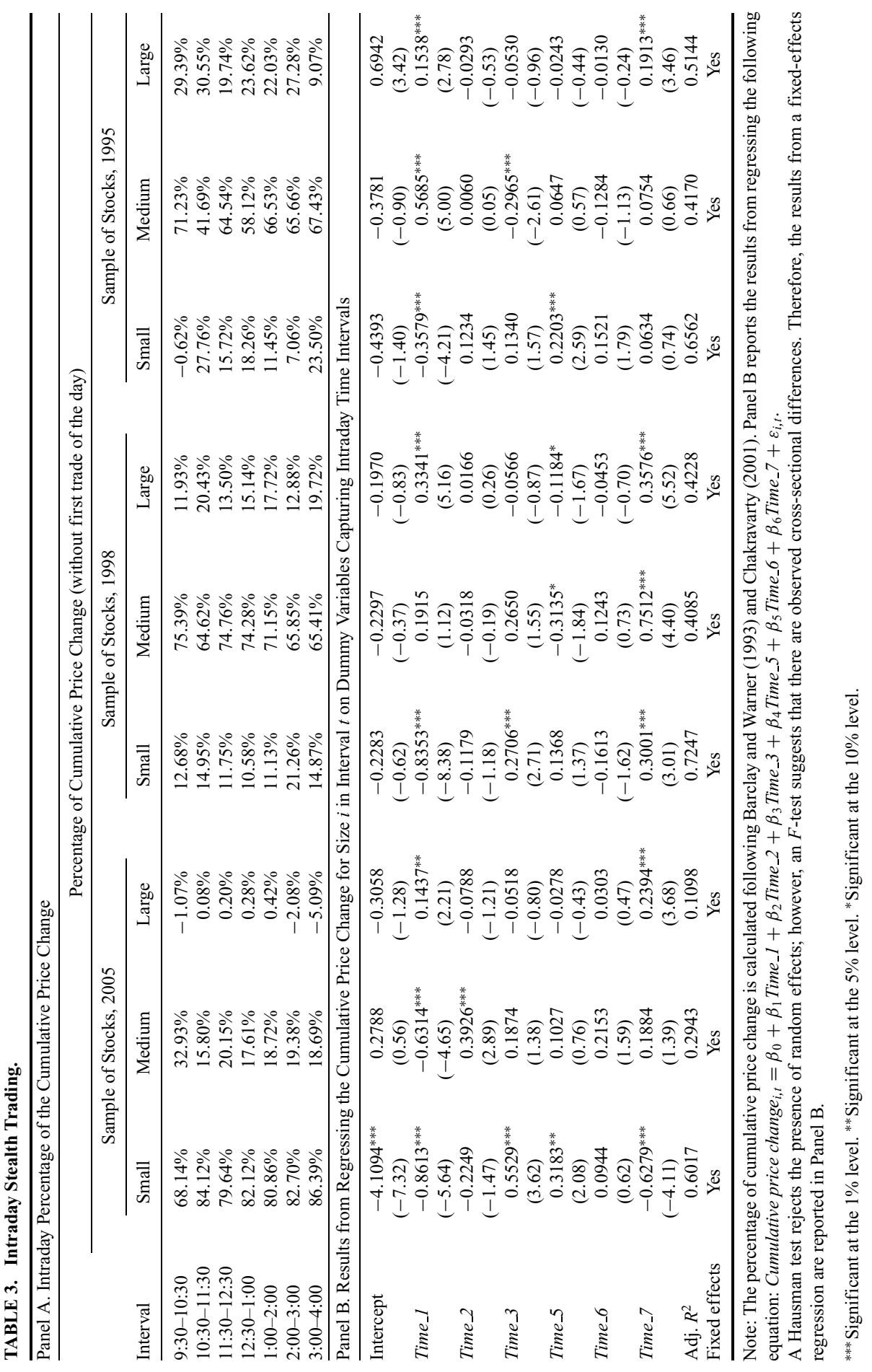


The dependent variable is the WPC for stock $i$ in interval $t$. The independent variables are six dummy variables that capture the first three and last three hours of the trading day. We estimate equation (1) for each of the different trade sizes and anticipate that the WPC for smaller trades will exhibit a reverse U-shaped intraday pattern and the WPC for larger trades will exhibit the familiar U-shaped pattern. A Hausman test rejects the presence of random effects, although we find observed differences across stocks. Therefore, we use a fixed-effects regression.

Table 3, Panel B reports the results from estimating equation (1). We find from the regression that small trades exhibit a significant reverse U-shaped intraday pattern (column 1). We find that large trades (column 3) drive the familiar U-shaped pattern in returns. In 1998 and 1995, we also find that price changes from large trades (columns 6 and 9) exhibit the familiar U-shaped pattern, which is consistent with our expectation. In 1998 and 1995, we find that the estimate for $\beta_{1}$ is significant and negative, suggesting that in the first hour of trading, price changes from small trades are significantly less than the omitted interval (12:30-1:00 pm). The results in Table 3 offer evidence for our expectation. That is, we find that large trades typically follow a U-shaped intraday pattern of returns. We also find, in our 2005 sample, that small trades move prices less in the first and last hours of trading than during the middle of the day, which suggests that larger trade sizes move prices more during the first and last hours of trading.

To provide a better test of our hypothesis using the data from 1995 and 1998, we use finer medium-sized categories. We expect that the distribution of informed trades shift from smaller medium-sized trades to larger medium-sized trades at the beginning and end of the day. Focusing on columns 4 through 9 of Table 4, Panel A, we do not find a clear pattern using the univariate WPC measures. Panel B provides the results of estimating equation (1) for the different medium-sized trades. In columns 1 through 3 of Panel B, we find that smaller medium-sized trades exhibit a reverse U-shaped pattern in price changes and a weak U-shaped pattern in price changes for larger medium-sized trades. Consistent with our hypothesis, for 1998, we find that larger medium-sized trades drive the U-shaped intraday pattern in price changes. In 1995, we find that medium-mid trades exhibit a U-shaped intraday pattern in price changes and medium-low trades exhibit a weak reverse U-shaped pattern in price changes. Tables 3 and 4 show that larger trades drive the familiar U-shaped pattern in intraday price changes.

Following Chakravarty (2001), we examine the average price changes for different trade sizes during the intraday. We scale the price change (in cents) by the unit volume for each trade to control for the endogeniety between price changes and trade size. Our expectations for the analysis using the average price changes are the same as before. Table 5 reports the analysis using Chakravarty's measure of average price change. Panel A examines the difference between the average price change in each interval and the intraday average price change. Consistent with our expectations, small-trade price changes exhibit a reverse U-shaped pattern and 


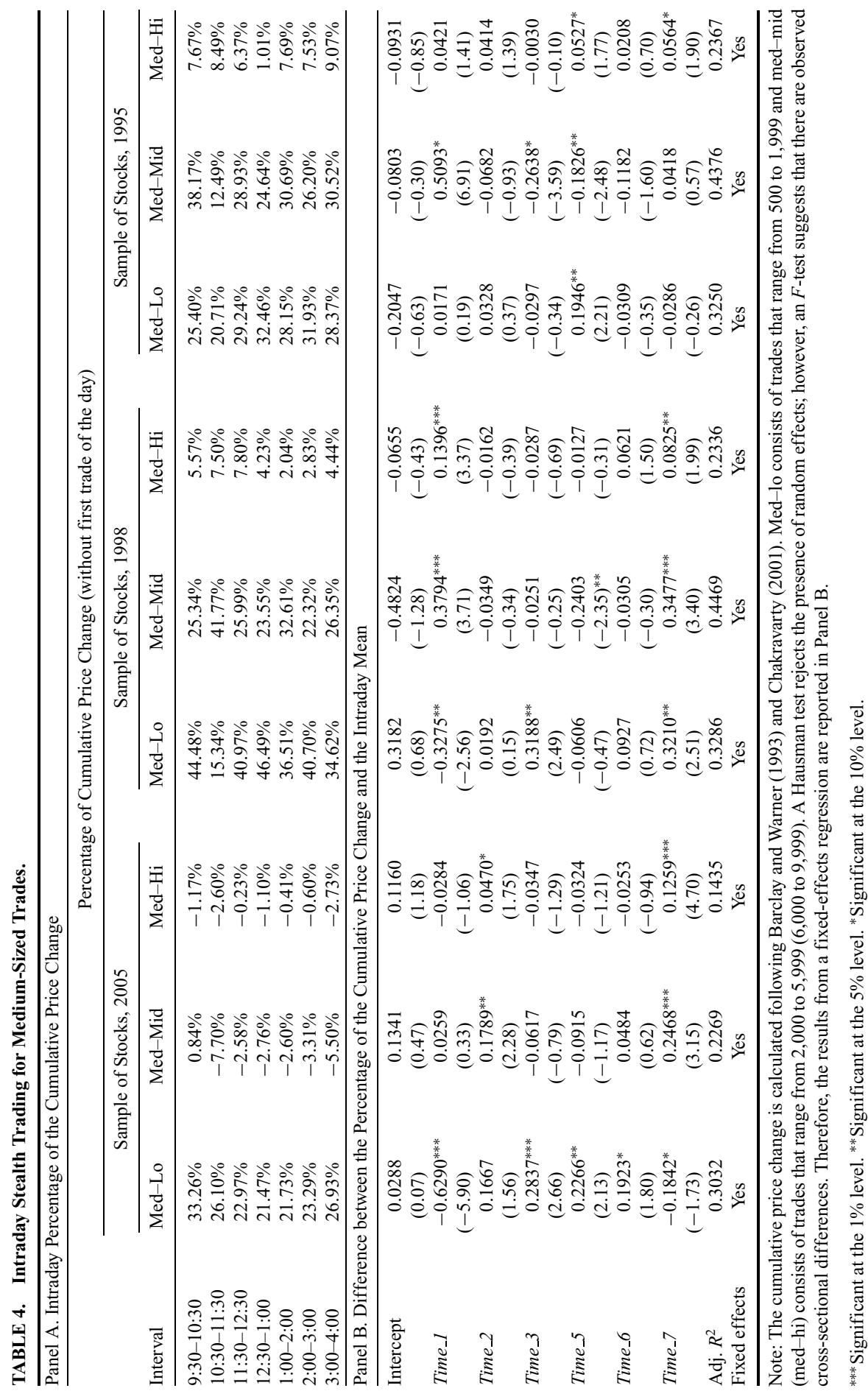




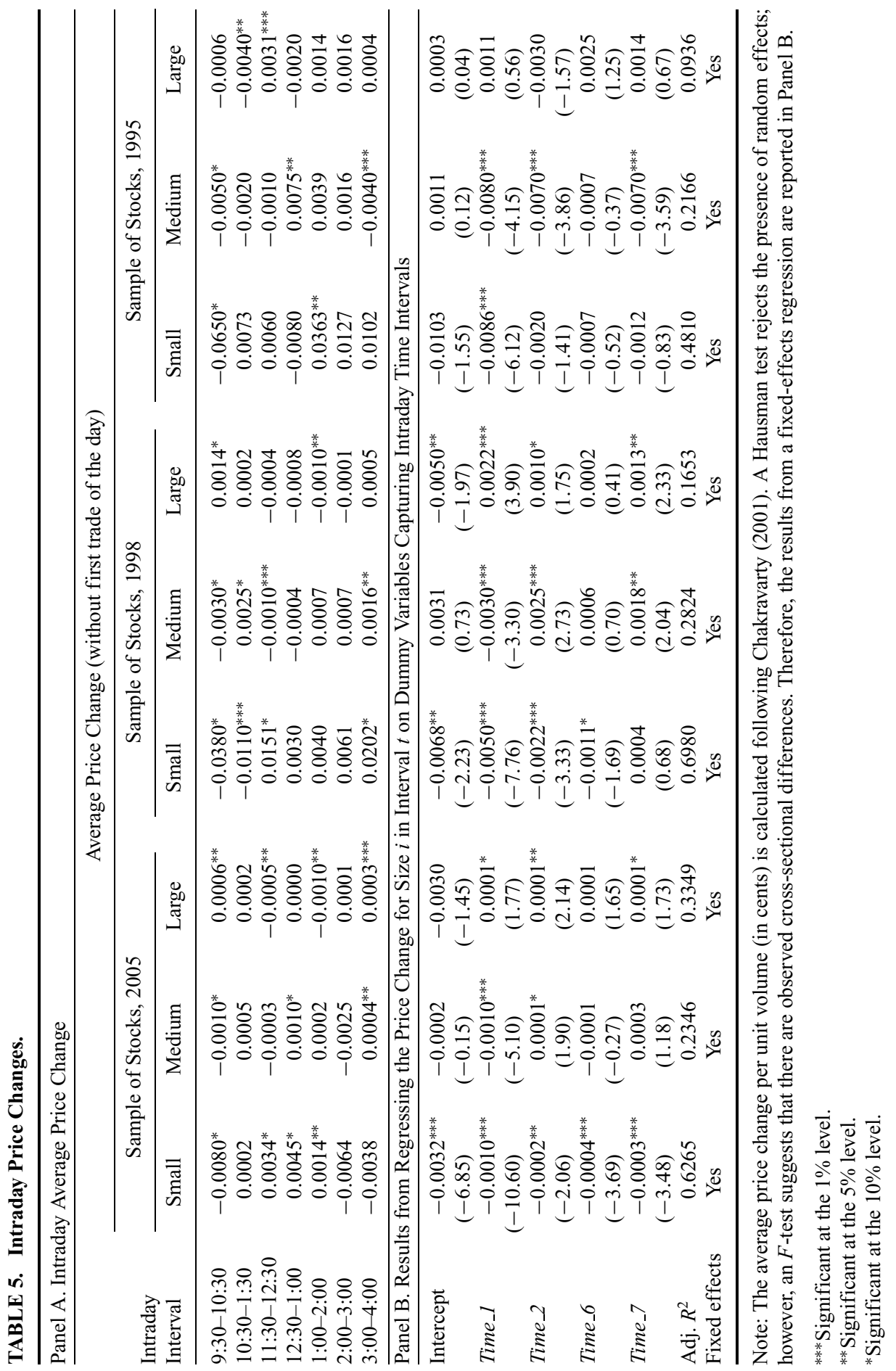


large-trade price changes have a significant U-shaped pattern for the 2005 sample. The results are generally robust to the 1998 subsample, as large-trade price changes are U-shaped. We also note that medium-trade price changes exhibit a reverse Ushaped pattern, suggesting that stealth trading in medium sizes occurs less during the beginning and end of the trading day.

We also estimate the following equation using a fixed-effects regression similar to equation (1).

$$
\begin{aligned}
\text { ave price change }_{i, t}= & \beta_{0}+\beta_{1} \text { Time }_{-} 1+\beta_{2} \text { Time } 22+\beta_{3} \text { Time } 6 \\
& +\beta_{4} \text { Time }_{-} 7+\varepsilon_{i, t} .
\end{aligned}
$$

The dependent variable is the average price change (in cents) per unit volume for stock $i$ in interval $t$. The independent variables are four dummy variables that capture the first two and last two hours of the trading day.

Panel B in Table 5 shows that large-trade price changes exhibit the familiar U-shaped intraday pattern for the 2005 and 1998 samples. Furthermore, smalland medium-trade price changes are significantly less at the beginning of the day, suggesting that stealth trading occurs less during the beginning of the day. Although we do not document a U-shaped pattern in large-trade price changes for the 1995 sample, we report a reverse U-shaped pattern in the medium-trade price changes, which is consistent with the univariate results and suggests that stealth trading in medium-sized trades occurs less at the beginning and the end of the day.

Table 6 reports the results for the different medium-sized categories. In the 1998 sample, we document that price changes from larger medium-sized trades exhibit the U-shaped intraday pattern. In the 1995 sample, we find that price changes from smaller medium-sized trades exhibit the reverse U-shaped intraday pattern. We do not find evidence of our expectation in larger medium-sized trades for the 1995 sample; however, in Table 1, we report that volume from large medium-sized trades is not U-shaped, which likely affects informed trading in different trade sizes.

Evidence of the positive relation between price changes and volume is important when examining the intraday patterns of returns and trading activity. Karpoff (1987) shows that positive price changes are directly related to volume. Thus far, we have shown that price changes from larger trades typically drive the U-shaped pattern in returns documented in Wood, McInish, and Ord (1985) and Harris (1986). We interpret our results to be consistent with the argument that informed traders will choose to stealth trade less during periods of high volume at the beginning and end of the day. We further test our conjecture by examining the relation between price changes and volume in each trade size.

To examine the relation between price changes and volume, we estimate the following equation: 


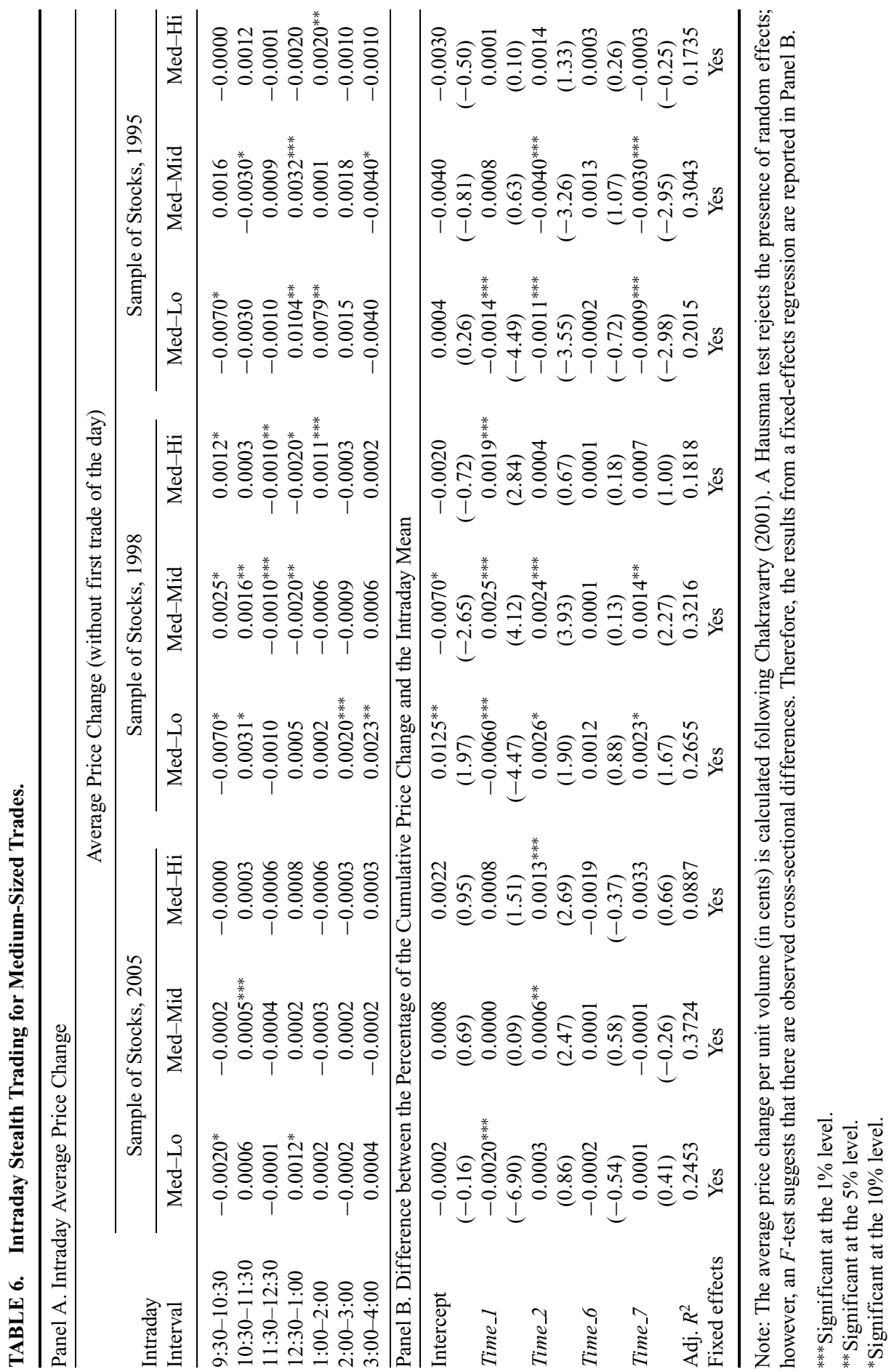


TABLE 7. Regression Results of Cumulative Price Change on Volume.

\begin{tabular}{|c|c|c|c|c|c|c|}
\hline \multicolumn{7}{|c|}{ Panel A. Sample of Stocks, 2005} \\
\hline & $\begin{array}{l}\text { Small } \\
\text { Trades }\end{array}$ & $\begin{array}{l}\text { Medium } \\
\text { Trades }\end{array}$ & $\begin{array}{l}\text { Large } \\
\text { Trades }\end{array}$ & $\begin{array}{l}\text { Med-Lo } \\
\text { Trades }\end{array}$ & $\begin{array}{l}\text { Med-Mid } \\
\text { Trades }\end{array}$ & $\begin{array}{c}\text { Med-Hi } \\
\text { Trades }\end{array}$ \\
\hline Intercept & $\begin{array}{l}-2.5302^{* * *} \\
(-10.16)\end{array}$ & $\begin{array}{l}-3.7754^{* * *} \\
(-6.51)\end{array}$ & $\begin{array}{l}-3.5756^{* * *} \\
(-13.77)\end{array}$ & $\begin{array}{l}-0.8109^{* * *} \\
(-7.50)\end{array}$ & $\begin{array}{l}-1.0661^{* * *} \\
(-3.96)\end{array}$ & $\begin{array}{l}-1.8983^{* * *} \\
(-6.53)\end{array}$ \\
\hline $\ln ($ volume $)$ & $\begin{array}{l}0.1539^{* * *} \\
(11.23)\end{array}$ & $\begin{array}{l}0.2252^{* * *} \\
(7.05)\end{array}$ & $\begin{array}{l}2.1539^{* * *} \\
(15.06)\end{array}$ & $\begin{array}{l}0.0495^{\text {*** }} \\
(8.32)\end{array}$ & $\begin{array}{l}0.0632^{* * *} \\
(4.26)\end{array}$ & $\begin{array}{l}0.1125^{\text {*** }} \\
(7.03)\end{array}$ \\
\hline $\operatorname{Adj} R^{2}$ & 0.1886 & 0.1580 & 0.2088 & 0.1671 & 0.1488 & 0.1566 \\
\hline Fixed effects & Yes & Yes & Yes & Yes & Yes & Yes \\
\hline \multicolumn{7}{|c|}{ Panel B. Sample of Stocks, 1998} \\
\hline Intercept & $\begin{array}{l}-0.0127 \\
(-3.92)\end{array}$ & $\begin{array}{l}-0.3362 \\
(-6.76)\end{array}$ & $\begin{array}{l}-2.7714 \\
(-14.16)\end{array}$ & $\begin{array}{l}-0.0306 \\
(-4.08)\end{array}$ & $\begin{array}{l}-0.0997 \\
(-4.93)\end{array}$ & $\begin{array}{l}-0.2058 \\
(-7.23)\end{array}$ \\
\hline $\ln ($ volume $)$ & $\begin{array}{l}0.0008 \\
(4.26)\end{array}$ & $\begin{array}{l}0.0262 \\
(8.98)\end{array}$ & $\begin{array}{c}0.1805 \\
(15.68)\end{array}$ & $\begin{array}{l}0.0028 \\
(6.28)\end{array}$ & $\begin{array}{l}0.0092 \\
(7.70)\end{array}$ & $\begin{array}{l}0.0143 \\
(8.56)\end{array}$ \\
\hline $\operatorname{Adj} R^{2}$ & 0.1705 & 0.1689 & 0.2250 & 0.1533 & 0.1601 & 0.1597 \\
\hline Fixed effects & Yes & Yes & Yes & Yes & Yes & Yes \\
\hline \multicolumn{7}{|c|}{ Panel C. Sample of Stocks, 1995} \\
\hline Intercept & $\begin{array}{l}-0.0119 \\
(-2.17)\end{array}$ & $\begin{array}{l}-0.9121 \\
(-10.77)\end{array}$ & $\begin{array}{l}-2.5679 \\
(-15.09)\end{array}$ & $\begin{array}{l}-0.0863 \\
(-5.90)\end{array}$ & $\begin{array}{l}-0.4144 \\
(-9.27)\end{array}$ & $\begin{array}{l}-0.4114 \\
(-11.82)\end{array}$ \\
\hline $\ln ($ volume $)$ & $\begin{array}{l}0.0008 \\
(2.39)\end{array}$ & $\begin{array}{l}0.0587 \\
(11.77)\end{array}$ & $\begin{array}{c}0.1657 \\
(16.55)\end{array}$ & $\begin{array}{l}0.0056 \\
(6.47)\end{array}$ & $\begin{array}{c}0.0267 \\
(10.14)\end{array}$ & $\begin{array}{l}0.0265 \\
(12.92)\end{array}$ \\
\hline $\operatorname{Adj} R^{2}$ & 0.1473 & 0.1907 & 0.2508 & 0.1554 & 0.1779 & 0.2047 \\
\hline Fixed effects & Yes & Yes & Yes & Yes & Yes & Yes \\
\hline
\end{tabular}

Note: The table reports the results of regressing the cumulative price change on the natural log of volume for each trade size: cumulative price change $e_{i, t}=\gamma_{0}+\gamma_{1}$ volume $_{i, t}+\varepsilon_{i, t}$. A Hausman test rejects the presence of the random effects, and an $F$-test suggests that there are observed differences across stocks. We report the fixed-effects estimates.

*** Significant at the $1 \%$ level.

$$
\text { price change }_{i, t, j}=\gamma_{0}+\gamma_{1} \text { volume }_{i, t}+\varepsilon_{i, t, j} .
$$

The dependent variables are the WPC and the average price change (in cents) per unit volume for stock $i$ in interval $t$ for trade-size category $j$. We regress the price change measures on volume for stock $i$ during interval $t$ and anticipate that the estimate for $\gamma_{1}$ will be increasing across increasing trade sizes. Using a Hausman test, we find observed differences across stocks and therefore estimate (3) using a fixed-effects regression.

Table 7 reports the results using the WPC as the dependent variable. Consistent with our expectation, we find that the estimate for $\gamma_{1}$ is monotonically increasing from small trades to large trades. We test the differences in the coefficients and find that in Panel A, the estimate $\gamma_{1}$ for small trades is significantly less (at the 5\% level) than for medium trades. Similarly, we find that the estimate $\gamma_{1}$ for large trades is significantly greater (at the $1 \%$ level) than for medium trades. We also report the results for the different medium trade sizes. We find that the 
TABLE 8. Regression Results of Average Price Change on Volume.

\begin{tabular}{|c|c|c|c|c|c|c|}
\hline \multicolumn{7}{|c|}{ Panel A. Sample of Stocks, 2005} \\
\hline & $\begin{array}{l}\text { Small } \\
\text { Trades }\end{array}$ & $\begin{array}{l}\text { Medium } \\
\text { Trades }\end{array}$ & $\begin{array}{l}\text { Large } \\
\text { Trades }\end{array}$ & $\begin{array}{c}\text { Med-Lo } \\
\text { Trades }\end{array}$ & $\begin{array}{l}\text { Med-Mid } \\
\text { Trades }\end{array}$ & $\begin{array}{c}\text { Med-Hi } \\
\text { Trades }\end{array}$ \\
\hline Intercept & $\begin{array}{l}0.0045^{* * *} \\
(3.28)\end{array}$ & $\begin{array}{l}-0.0001 \\
(-0.11)\end{array}$ & $\begin{array}{l}-0.0200^{\text {**** }} \\
(-3.64)\end{array}$ & $\begin{array}{l}0.0077^{*} \\
(1.70)\end{array}$ & $\begin{array}{l}-0.0050 \\
(-1.39)\end{array}$ & $\begin{array}{l}-0.0130^{* *} \\
(-1.98)\end{array}$ \\
\hline $\ln ($ volume $)$ & $\begin{array}{l}-0.0007^{* * *} \\
(-6.22)\end{array}$ & $\begin{array}{l}0.00000 \\
(0.04)\end{array}$ & $\begin{array}{l}0.0015^{* * *} \\
(3.43)\end{array}$ & $\begin{array}{l}-0.0007^{* *} \\
(-1.95)\end{array}$ & $\begin{array}{l}0.0005^{*} \\
(1.77)\end{array}$ & $\begin{array}{l}0.0014^{* *} \\
(2.51)\end{array}$ \\
\hline $\operatorname{Adj} R^{2}$ & 0.6148 & 0.2211 & 0.3362 & 0.2276 & 0.3713 & 0.0873 \\
\hline Fixed effects & Yes & Yes & Yes & Yes & Yes & Yes \\
\hline \multicolumn{7}{|c|}{ Panel B. Sample of Stocks, 1998} \\
\hline Intercept & $\begin{array}{l}0.0307^{* * *} \\
(3.08)\end{array}$ & $\begin{array}{l}-0.0010 \\
(-0.73)\end{array}$ & $\begin{array}{l}-0.0390^{\text {**** }} \\
(-4.64)\end{array}$ & $\begin{array}{l}0.0027 \\
(1.28)\end{array}$ & $\begin{array}{l}-0.0062^{* * *} \\
(-6.74)\end{array}$ & $\begin{array}{l}-0.0420^{* * *} \\
(-4.25)\end{array}$ \\
\hline $\ln ($ volume $)$ & $\begin{array}{l}-0.0035^{* * *} \\
(-4.08)\end{array}$ & $\begin{array}{l}0.0001 \\
(1.03)\end{array}$ & $\begin{array}{l}0.0031^{\text {**** }} \\
(4.32)\end{array}$ & $\begin{array}{l}-0.0001 \\
(-0.71)\end{array}$ & $\begin{array}{l}0.0005^{* * *} \\
(6.34)\end{array}$ & $\begin{array}{l}0.0037^{\text {*** }} \\
(4.28)\end{array}$ \\
\hline $\operatorname{Adj} R^{2}$ & 0.6909 & 0.2734 & 0.1655 & 0.2539 & 0.3247 & 0.1851 \\
\hline Fixed effects & Yes & Yes & Yes & Yes & Yes & Yes \\
\hline \multicolumn{7}{|c|}{ Panel C. Sample of Stocks, 1995} \\
\hline Intercept & $\begin{array}{l}0.0487^{* *} \\
(2.47)\end{array}$ & $\begin{array}{l}0.0096^{* * *} \\
(3.55)\end{array}$ & $\begin{array}{l}-0.0260 \\
(-0.90)\end{array}$ & $\begin{array}{l}0.0159^{* * *} \\
(3.59)\end{array}$ & $\begin{array}{l}-0.0130 \\
(-0.79)\end{array}$ & $\begin{array}{l}-0.0290^{* *} \\
(-1.96)\end{array}$ \\
\hline $\ln ($ volume $)$ & $\begin{array}{l}-0.0057^{* * *} \\
(-3.28)\end{array}$ & $\begin{array}{l}-0.0009^{* * *} \\
(-3.87)\end{array}$ & $\begin{array}{l}0.0025 \\
(0.98)\end{array}$ & $\begin{array}{l}-0.0015^{* * *} \\
(-3.85)\end{array}$ & $\begin{array}{l}0.0007 \\
(0.50)\end{array}$ & $\begin{array}{l}0.0025^{*} \\
(1.92)\end{array}$ \\
\hline $\operatorname{Adj} R^{2}$ & 0.4748 & 0.2109 & 0.0915 & 0.1967 & 0.2972 & 0.1740 \\
\hline Fixed effects & Yes & Yes & Yes & Yes & Yes & Yes \\
\hline
\end{tabular}

Note: The table reports the results of regressing the average price change per unit volume (in cents) on the natural $\log$ of volume for each trade size: average price change $e_{i, t}=\gamma_{0}+\gamma_{1}$ volume $_{i, t}+\varepsilon_{i, t}$. The independent variable in the first regression is the natural log of the trading volume. A Hausman test rejects the presence of the random effects, and an $F$-test suggests that there are observed differences across stocks. We report the fixed-effects estimates.

*** Significant at the $1 \%$ level.

** Significant at the $5 \%$ level.

* Significant at the $10 \%$ level.

relation between price changes and volume is monotonically increasing across the increasing medium trade sizes. ${ }^{9}$ When examining Panels B and C, we find that the estimate $\gamma_{1}$ is also increasing across increasing trade sizes, supporting our expectation. When examining the different medium-sized trades, we generally find evidence of an increasing relation between price changes and volume (in Panel $\mathrm{C}$, the estimate $\gamma_{1}$ does not increase from medium-middle trades to medium-high trades).

\footnotetext{
${ }^{9} \mathrm{We}$ do not find a significant difference between the estimate $\gamma_{1}$ for medium-low trades and mediummiddle trades. However, we find that the estimate $\gamma_{1}$ for medium-high trades is significantly greater (at the $1 \%$ level) than for medium-middle trades.
} 
Table 8 reports the results from estimating equation (3) using the average price change as the dependent variable. Similar to the findings in Table 7, we find that the estimate $\gamma_{1}$ is monotonically increasing across trade sizes. Panel A reports an inverse relation between price changes and volume for small trades, no significant relation for medium trades, and a positive relation for large trades. The results are also apparent in Panel B. In Panel C we find that small-trade price changes and medium-trade price changes are negatively related to volume. However, the relation is significantly more negative for small trades (at the $1 \%$ level). We do not find that large-trade price changes are statistically different from zero, though the estimate is positive. When examining the different medium-sized trades, we find that the relation between price changes and volume is monotonically increasing across increasing medium trade sizes.

The results in Table 8 confirm the findings in Table 7 and support the notion that stealth trading occurs less during periods of high volume. To our knowledge, we are the first to document that large trades drive the positive relation between price changes and volume. Furthermore, the familiar U-shaped pattern in returns is apparent in large trades. We argue that ex ante theory predicts that informed traders, who do not wish to reveal their information to the market, will spread trades across time (Kyle 1985) as well as concentrate their trading during periods of high volume (Admati and Pfleiderer 1988). Therefore, the distribution of informed trading will shift from smaller trades to larger trades during periods of high volume.

\section{Conclusion}

We determine which trades drive the familiar U-shaped pattern in intraday price changes documented by Wood, McInish, and Ord (1985) and Harris (1986). After investigating stocks in the different tick-size environments, we document that large trades drive the U-shaped pattern in intraday returns as price changes from larger (smaller) trades are higher (lower) at the beginning and end of the day. The results are consistent with ex ante literature that predicts (1) that informed traders will execute trades during periods of high volume to camouflage their trades (Admati and Pfleiderer 1988) and (2) that profit-maximizing informed traders will optimize their trading strategy, dynamically spreading their trades over time to capitalize on their private information (Kyle 1985; Barclay and Warner 1993). Although some informed traders are likely breaking up trades into smaller sizes so as to not reveal their information, informed traders are less inclined to execute smaller trades during periods of high volume. Therefore, we document that the distribution of informed trades shifts from smaller trades to larger trades during high beginning- and endof-day volume.

The literature documents a persistent, positive relation between price changes and volume. We find that the relation between price changes and volume 
is increasing across trade sizes. Price changes from smaller trades are negatively related to volume whereas price changes from larger trades are positively related to volume, findings consistent with our predictions. We believe the data offer support for the hypothesis that profit-maximizing investors stealth trade less frequently during periods of high volume because volume provides a sufficient camouflage for the investor's information. That is, informed investors use large trades when markets are thick; however, it appears that informed investors stealth trade during periods of low volume (Barclay and Warner 1993; Kyle 1985; Admati and Pfleiderer 1988).

\section{References}

Admati, A. and P. Pfleiderer, 1988, A theory of intraday patterns: Volume and price variability, Review of Financial Studies 1, 3-40.

Alexander, G. J. and M. A. Peterson, 2007, An analysis of trade-size clustering and its relation to stealth trading, Journal of Financial Economics 84, 435-71.

Back, K. and H. Pedersen, 1998, Long-lived information and intraday patterns, Journal of Financial Markets 1, 385-402.

Barclay, M. and T. Hendershott, 2003, Price discovery and trading after hours, Review of Financial Studies $16,1041-73$.

Barclay, M. and J. B. Warner, 1993, Stealth trading and volatility: Which trades move prices? Journal of Financial Economics 34, 281-306.

Blau, B., B. Van Ness, and R. Van Ness, 2008, The optimal trade-size choice of short sellers: Theory and evidence, Working paper, Brigham Young University.

Cao, C., E. Ghysels, and F. Hatheway, 2000, Price discovery without trading: Evidence from the Nasdaq preopening, Journal of Finance 55, 1339-65.

Chakravarty, S., 2001, Stealth trading: Which trader's trades move prices? Journal of Financial Economics 61, 289-307.

Chakravarty, S. and J. McConnell, 1997, An analysis of prices, bid/ask spreads and did/ask depths surrounding Ivan Boesky's illegal trading in Carnation's stock, Financial Management 26, 18 -34.

Chakravarty, S. and J. McConnell, 1999, Does insider trading really move stock prices? Journal of Financial and Quantitative Analysis 34, 191-209.

Chan, K., W. Christie, and P. Schultz, 1995, Market structure and the intraday pattern of bid-ask spreads for NASDAQ securities, Journal of Business 68, 35-60.

Chung, K., B. Van Ness, and R. Van Ness, 1999, Limit orders and the bid-ask spread, Journal of Financial Economics 53, 255-87.

Copeland, T., 1976, A model of asset trading under the assumption of sequential information arrival, Journal of Finance 31, 1149-68.

Copeland, T., 1977, A probability model of asset trading, Journal of Financial and Quantitative Analysis 12, 563-78.

Cornell, B. and E. Sirri, 1992, The reaction of investors and stock prices to insider trading, Journal of Finance 47, 1031-59.

Foster, F., and S. Viswanathan, 1993, Variations in trading volume, return volatility, and trading costs: Evidence on recent price formation models, Journal of Finance 48, 187-211.

Gonzalo, J. and C. Granger, 1995, Estimation of common long-memory components in cointegrated systems, Journal of Business and Economic Statistics 13, 27-36.

Hansch, O. and H. Choe, 2007, Which trades move stock prices? Stealth trading revisited, Working paper, Pennsylvania State University.

Harris, L., 1986, A transaction data study of weekly and intradaily patterns of stock returns, Journal of Financial Economics 16, 99-118. 
Hasbrouck, J., 1988, Trades, quotes, inventories and information, Journal of Financial Economics 22, 229-52.

Hasbrouck, J., 1995, One security, many markets: Determining the contributions to price discovery, Journal of Finance 50, 1175-99.

Huang, R., 2002, The quality of ECN and NASDAQ market maker quotes, Journal of Finance 57, 12851319.

Hvidkjaer, S., 2006, Small trades and the cross-section of stock returns, Working paper, University of Maryland.

Jain, P. and G. Joh, 1988, The dependence between hourly prices and trading volume, Journal of Financial and Quantitative Analysis 23, 269-83.

Karpoff, J., 1987, The relation between price changes and trading volume: A survey, Journal of Financial and Quantitative Analysis 22, 109-26.

Kyle, A., 1985, Continuous auctions and insider trading, Econometrica 53, 1315-35.

Lo, A. and A. MacKinlay, 1990, When are contrarian profits due to stock market overreaction? Review of Financial Studies 3, 175-206.

Wood, R., T. McInish, and J. Ord, 1985, An investigation of transaction data for NYSE stocks, Journal of Finance 40, 723-40. 